\title{
The costs of being placed on hold
}

\section{Budget battles in the US Congress are precipitating higher costs at government facilities, including federal funding of biomedical research.}

B rinksmanship is once again at the fore in the passage of the US government budget for 2011. Partisan bickering in Congress has hampered efforts to finalize a federal budget and send it to President Obama for his approval. At odds are whether and how to trim non-defense discretionary spending, which constitutes roughly $20 \%$ of the budget (in fiscal year 2010 (FY2010), this amounted to $\$ 660$ billion). Republicans want to scale back such spending by $\$ 61$ billion, which if enacted could necessitate cuts of $10 \%$ or more in the affected government agencies. President Obama has stated he would veto such deep spending cuts, noting it would endanger recovery of the fragile economy; these comments have been echoed by the US Federal Reserve Chairman Ben Bernanke and other independent economists. Both Democrats and Republicans, however, realize tackling federal budget deficits is necessary, and spending cuts of $\$ 10$ billion have already been approved.

Funding for the National Institutes of Health (NIH) and other federal laboratories falls within the discretionary budget now under debate. The Obama budget has requested $\$ 31.83$ billion for the NIH in FY2012, which is a $3.4 \%$ increase over spending in FY2010. The nonpartisan Congressional Budget Office prepared a list of options on how to trim discretionary spending over a multi-year period (http://www.cbo. gov/ftpdocs/120xx/doc12085/03-10-ReducingTheDeficit.pdf), which includes two scenarios for the NIH (option 33 in their report). One scenario restricts growth to $1 \%$ per fiscal year; the other rolls back spending to the amounts of FY2003 (a 13\% cut from the NIH budget of FY2010, or nearly $\$ 4$ billion), after which funding would be increased at the rate of inflation. Such cuts in the latter scenario, if enacted, would surely alter the US biomedical research environment. Although the Congressional Budget Office report states these options are not recommendations, its projections offer policymakers real numbers indicating how their decisions will affect the various funding programs.

Since the current fiscal year began on 1 October 2010, lawmakers have passed six temporary spending bills, called 'continuing resolutions', designed to keep the government running in lieu of a 2011 budget. The latest continuing resolution, passed 17 March 2011, is due to expire 8 April 2011 if it is not extended by yet another temporary measure or a budget is approved. The votes to approve even the temporary spending bills are growing increasingly polarized, prompting fears of a government shutdown. This situation would require all nonessential government activities be halted until a new budget is passed. Memories of a similar budget showdown that occurred in 1995, which forced the government to furlough workers and shutter federal agencies for several weeks, suggest that such a scenario is not out of the question.

Although $80 \%$ of the research funded by the NIH is done at extramural biomedical laboratories, a substantial and productive intramural research program exists on the NIH campuses. These laboratories are subject to a government shutdown if the budget impasse is not resolved in time. The budget stalemate has prompted contingency planning by intramural NIH research teams should the laboratories face a mandated shutdown. Laboratory chiefs would have to identify at most two fulltime employees as emergency personnel (one being themselves) who would be responsible for maintaining critical laboratory functions in the event of a furlough. Animal care technicians and clinical care providers are considered essential. All others, including students and postdoctoral fellows, who constitute a large contingent of the NIH staff, would be barred from the campus and would be subject to fines should they attempt to enter their laboratories. This requirement places an incredibly large burden on the designated essential people and risks loss of ongoing experiments because of the limited manpower available. As postdoctoral fellows are considered contract workers, they have no guarantees that they will receive paychecks if they are furloughed during a government shutdown. Simple ordering and delivery of supplies would be halted. Government employees traveling to conferences or offsite facilities would be asked to leave immediately and/or forfeit registration fees or travel deposits made in advance. Extramural research programs would also be affected by a government closure, as grant study sections would be postponed or canceled. Any award payouts not already processed, such as NIH stipends to research fellows working at extramural academic sites, could be delayed.

What might not be so apparent is that preparing such contingency plans and operating under recurrent temporary funding provisions has already exacted costs for ongoing research in federal laboratories. These costs include lost productivity because of time taken away from actual research and the inability to initiate or continue long-term experiments because of uncertainty about whether the budget will be passed on time. For example, some vaccination studies involving animal immunization and analyses of efficacy and immunologic memory have been put on hold for fear of an impending laboratory closure at some future date. Equipment requisition and repair is being placed on hold. Costs associated with higher travel fares have been incurred by government employees because of restrictions on booking travel too near expiring temporary resolutions.

The government shutdown in 1995 ultimately resulted in higher costs. It is therefore imperative that lawmakers resolve the budget dilemma before the continuing resolutions run out. Despite proclamations of working to save taxpayer dollars, the continuing budget impasse is generating more wasteful spending. Sadly, many taxpayers fail to realize how much extra they are actually paying by listening to the politicians argue. 